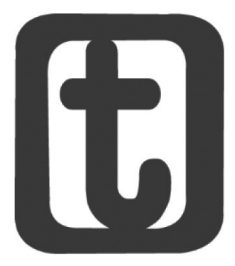

\title{
ÉTICA E SERVIÇO SOCIAL: UM ITINERANTE CAMINHAR
}

\author{
ETHICS AND SOCIAL SERVICE: AN ITINERANT WALK
}

\author{
Adrianyce A. Silva de Sousa' \\ Silvana Mara Morais dos Santos² \\ Priscila Cardoso 3
}

\section{RESUMO}

O presente artigo tem por objetivo discutir, a partir da experiência do Projeto Itinerante desenvolvido pela Gestão da ABEPSS 2011-2012 em parceria com o CFESS, a questão da ética na formação profissional em Serviço Social na atualidade. Para tanto, a elaboração deste material partiu da compilação e sistematização dos Relatórios dos Regionais da ABEPSS das experiências do Projeto ABEPSS Itinerante, no que se refere ao módulo 04, "A Ética na Formação Profissional”. Assim, apontamos aqui um conjunto de questões que atravessam e problematizam a formação dos futuros assistentes sociais, à luz de uma necessária reflexão ética.

Palavras-chave: Ética. Serviço Social. Formação.

1 Doutora em Serviço Social pela Universidade Federal do Rio de Janeiro - UFRJ. Profa Adjunta da ÚnB - Curso de Serviço Social. Coordenadora do Núcleo de Estudos, Pesquisa sobre Teoria Social, Trabalho e Serviço Social - NUTSS. Vicepresidente Regional da ABEPSS Centro-Oeste Gestão 2011-2012

2 Doutora em Serviço Social pela Universidade Federal de Pernambuco - UFPE. Prof ${ }^{a}$ do curso de Graduação e Pós-Graduação em Serviço Social da UFRN. Coordenadora do Grupo de Estudos e Pesquisa em Trabalho, Ética e Direitos e membro do GTP - ABEPSS - Ética, Direitos Humanos e Serviço Social. Ministrou o Módulo IV - “A Ética na Formação Profissional”, no Projeto ABEPSS Itinerante, na turma do Regional Nordeste.

3 Doutora em Serviço Social pela Pontificia Universidade Católica de São Paulo. Profa Adjunta da UNIFESP/BS - Curso de Serviço Social. Co-Coordenadora do Núcleo de Estudos, Pesquisa e Extensão sobre Ética e Trabalho Profissional NEPETP. Membro do Núcleo de Bioética do Campus BS. Ministrou o Módulo IV - "A Ética na Formação Profissional”, no Projeto ABEPSS Itinerante, nas turmas dos Regionais Centro-Oeste e Norte. 


\section{ABSTRACT}

This article aims to discuss, from the experience developed by Projeto ABEPSS Itinerante in 2011-2012 management in partnership with CFESS, the question of ethics in social service professional formation today. For this purpose, the preparation of this material came from the collection and systematization of the Reports of ABEPSS Regionals about ABEPSS Itinerante experiences, with regard to module 04, "Ethics in Professional Formation." So, here we point out a number of issues that cross and question future social workers formation in the light of a necessary ethical reflection.

Keywords: Ethics. Social Service. Formation.

Submetido em 31/03/2013

Aceito em 02/06/2013

Feliz aquele que transfere o que sabe e aprende o que ensina.

Cora Coralina

\section{INTRODUÇÃO}

Qualquer análise acerca da experiência do projeto - ABEPSS Itinerante: as diretrizes curriculares e o projeto de formação profissional do Serviço Social - será necessariamente indicativa e aproximativa dada à riqueza e diversidade das questões vivenciadas nas atividades desenvolvidas em todo o Brasil pelos regionais da ABEPSS. Dessa forma, apresentamos aqui elementos reflexivos, com o objetivo de contribuir na análise dessa primeira experiência de materialização desse projeto que traz em sua formulação dois aspectos presentes no Serviço Social brasileiro, notadamente, na construção cotidiana do projeto ético-político profissional.

O primeiro é o papel político de direção fundamental exercido por nossas entidades representativas. É quase desnecessário socializar que a efetivação desse projeto não poderia prescindir da competente coordenação político-administrativa da ABEPSS (direção nacional e regionais) com o reconhecimento de todo o trabalho coletivo realizado por gestões anteriores, que se dedicaram a elaborar as diretrizes curriculares e, em outro momento histórico, avaliar sua implementação e acompanhar os desdobramentos de um processo que é complexo e que depende da existência de um conjunto de condições objetivas e subjetivas no universo das unidades de formação acadêmica (UFA). Também 
destacamos o imprescindível apoio do Conselho Federal de Serviço Social (CFESS) e a participação dos conselhos regionais, como parceiros na defesa da formação e do exercício profissionais com qualidade. $O$ segundo aspecto refere-se ao compromisso dos/as que se envolveram nessa iniciativa, seja na condição de participantes ou ministrantes dos módulos. Houve explícita dedicação de tempo, atitude democrática e respeito na socialização das experiências, polêmicas, tensões e desafios.

Este artigo busca, pois, contribuir diretamente na reflexão sobre a materialização do Módulo IV - "A Ética na Formação Profissional", do Projeto ABEPSS Itinerante e foi escrito de modo compartilhado, reunindo nossas experiências na condição de colaboração na construção do conteúdo/ementa, ministrantes do módulo em regiões distintas (Centro-Oeste e Nordeste) ou vice-presidente regional da ABEPSS - Região Centro-Oeste no período 2011-2012. O que aqui apresentaremos tem a perspectiva de afirmar a relevância e pertinência histórica desse projeto e contribuir mais diretamente no debate da ética, entendendo-o profundamente articulado ao conteúdo dos demais módulos e aos grandes desafios contemporâneos que temos a enfrentar, num mundo hegemonizado pelo capital, que a tudo mercantiliza e em seus processos engendra formas de banalização da vida humana, por meio da reprodução da exploração do trabalho e de inúmeras modalidades de opressão.

Como nos lembrou a ABEPSS, em poesia incluída em seu caderno de textos, fomos construindo uma "aula de vôo" porque

“o conhecimento é assim:
ri de si mesmo
e de suas certezas.
É meta de forma
metamorfose
movimento
fluir do tempo
que tanto cria como arrasa
a nos mostrar que para o vôo
é preciso tanto o casulo
como a asa” (Mauro lasi)




\section{A ÉTICA NA FORMAÇÃO PROFISSIONAL: POLÊMICAS E DESAFIOS}

Após a compilação dos dados apresentados nos Relatórios dos Regionais, no que se refere ao Módulo IV - "A Ética na Formação Profissional", do Projeto ABEPSS Itinerante, de partida, entendemos que um pressuposto deve ser observado dado sua determinação sob o que vamos analisar: trata-se mesmo da contrarreforma da educação, sentida na precarização sistemática presente nas universidades públicas e privadas, guardadas particularidades de cada modalidade dessas, no galopante aumento dos cursos de Serviço Social em instituições privadas e, mais ainda, nos cursos de graduação a distância. O que aqui se coloca em questão é, pois, a relação entre essa objetividade - que determina e permeia a realidade da formação profissional em todo o país - e seu peso ideológico na formação/informação das consciências do corpo discente e docente. Ou seja, quando pensamos a dimensão ética, tal como conquistado nas Diretrizes Curriculares de 1996, somos levadas a questionar o que significa formar assistentes sociais num contexto de grande investimento pelas classes dominantes e Estado, na socialização de um universo ideológico e cultural, particularizado na defesa dos interesses do capital e na ruptura com valores civilizatórios, cuja consequência mais imediata é o massivo esvaziamento das capacidades críticas e da problematização em torno da intervenção profissional. A formação profissional precisa ser capaz de buscar uma coerência com este universo formativo/informativo. Nas palavras de lamamoto (2009, p. 42, grifo do autor),

A massificação e a perda de qualidade da formação universitária estimulam o reforço de mecanismos ideológicos que facilitam a submissão dos profissionais às 'normas do mercado', redundando em um processo de despolitização da categoria, favorecido pelo isolamento vivenciado no ensino à distância e na falta de experiências estudantis coletivas na vida universitária.

Muitas são as polêmicas, dificuldades, tensões e divergências presentes no cotidiano das UFA em torno do projeto de formação profissional. Mais ainda se considerarmos que, do ponto 
de vista geral, a formação profissional em Serviço Social aponta para uma crítica constante ao padrão vigente de sociabilidade e um rigor no que se refere às nossas atribuições e competências profissionais, que devem ser postas em movimento, a partir de um horizonte teórico-metodológico, ético-político e técnico-operativo. Isso porque, neste contexto, torna-se bastante desafiador formar e, ao mesmo tempo, contribuir com processos de desconstrução de (des)valores próprios da reprodução do ethos burguês, que é cada vez mais intensificado e defendido por amplos setores sociais. Acrescente-se um conjunto de problematizações que derivam, também, das condições de trabalho de cada UFA, da inserção ou não do/a docente no debate da profissão e, em particular, da ética em nível nacional, bem como das próprias condições da formação acadêmica dos/as docentes e das condições de vida material e cultural de docentes e discentes.

Esta questão é adensada quando verificamos ademais todas as contribuições e potencialidades postas pelo Projeto ABEPSS Itinerante, o quanto ainda nos é exigido um duplo movimento: de um lado, seguir avançando na consolidação das Diretrizes Curriculares por meio da ampla socialização do seu significado, lógica-interna e pressupostos fundamentais, que ainda hoje se apresentam como enigmas para muitos dos envolvidos no processo de formação; e, de outro, a disputa em torno da direção social-estratégica dessa formação. Tão verdadeira é a atualidade desse movimento expressa na fala de um docente participante

Sou outro docente, depois do "ABEPSS-itinerante"; nunca pensei o quanto a ética era, de fato, central e como é difícil e necessário construir formadores para multiplicá-la; pena que muitos colegas não puderam participar (Relatório da Regional SUL I da atividade ABEPSS Itinerante, 2012, p. 8).

Em todos os Relatórios dos Regionais, é destacável que, tanto no campo das expectativas como no campo das contribuições que os/as participantes realizariam em seus locais de trabaIho após o curso, há a presença marcante da qualificação com vistas ao fortalecimento do projeto ético-político e às modificações estruturais nos cursos em suas diversas dimensões. 
O que significa, então, essa qualificação no que se refere à dimensão ética e a garantia da sua transversalidade na formação?

Nos relatórios de todos os regionais não existe, pelo menos não de maneira expressiva, incompreensão do lugar da dimensão ética na formação profissional a partir das Diretrizes Curriculares de 1996. É, pois, um “consenso" a conformação geral deste eixo no sentido do seu significado

Numa perspectiva de transversalidade, sendo abordada em todas as disciplinas ao longo do curso (Docente - Relatório Regional Norte da Atividade ABEPSS Itinerante, 2012, p. 14).

A ética deve ser entendida como eixo privilegiado pela abordagem e discussões que permeiam os conteúdos a serem direcionados e que garantam a formação profissional (Relatório Regional Leste da Atividade ABEPSS Itinerante, 2012, p. 27).

Acredito que de forma a atravessar todo o currículo, disseminada, sem deixar de existir uma ou duas disciplinas específicas que tratem a ética na sua generalidade e a ética profissional (Docente - Relatório Regional Centro-Oeste da Atividade ABEPSS Itinerante, 2012, p. 51).

Contudo, quando pensamos do ponto de vista da lógica interna e dos seus pressupostos, comparece aqui as dificuldades ainda existentes na formação e reatualizadas pelas problematizações feitas anteriormente. No sentido da garantia desta transversalidade, os Relatórios dos Regionais Centro-Oeste, Norte, Sul II e Nordeste destacam que ela não acontece ou acontece timidamente. Somente os Relatórios dos Regionais Leste e Sul I observam que, em suas realidades, essa dimensão está garantida, apesar das dificuldades.

Enquanto disciplina, a Ética é trabalhada em apenas uma no âmbito da matriz curricular. Porém, em todas as disciplinas os professores promovem a reflexão da importância da postura ética e da leitura da realidade a partir dos princípios éticos propostos pelo Código de Ética profissional (Docente - Relatório Regional Sul I da Atividade ABEPSS Itinerante, 2012, p. 11). 
Na concepção do curso, no projeto pedagógico, que possui como um dos pontos norteadores a Ética esteve sempre presente e a equipe busca de forma incisiva a interdisciplinaridade entre os eixos - núcleos de formação. Dessa forma, desde os primeiros dois períodos os discentes vivenciam a disciplina formação do trabalho profissional e nesta são iniciadas as primeiras discussões sobre que profissão é essa - a de Assistente Social, bem como os documentos: regulamentação da profissão, código de ética e que sentido o mesmo possui nas ações da vida cotidiana do Assistente Social. Neste momento, os alunos fazem entrevistas com assistentes sociais nos diversos espaços ocupacionais para conhecer a profissão e como no fazer profissional, os princípios éticos estão presentes (Docente - Relatório Regional Leste da Atividade ABEPSS Itinerante, 2012, p. 27).

É importante observar que quando são elencados os componentes curriculares que tratam desse conteúdo, a dimensão da transversalidade fica majoritariamente circunscrita a um leque específico de disciplinas, em particular a disciplina de Ética que aparece a partir das seguintes denominações: Ética em Serviço Social; Ética Profissional; Ética I; Ética Profissional e Serviço Social; Ética e Serviço Social; Fundamentos Filosóficos e Serviço Social; Ética Profissional I e II; e Fundamentos Teóricos, Metodológicos e Ético-políticos do Serviço Social (FHTM) I, II, III, IV.

Apenas dois Relatórios referiram-se especificamente a relação da ética com as disciplinas de FHTM. Um dos desafios postos está de fato na constituição dessas disciplinas como um diferencial ao que estava posto no Currículo de 1982, que segmentava a Teoria do Método e da História. Na atual lógica das Diretrizes Curriculares de 1996, trata-se muito mais do que uma articulação mecânica, mas efetivamente da necessária relação de tratamento dos conteúdos numa perspectiva de totalidade.

Assim, precisamos avançar nas estratégias de superação da dicotomia entre história, teoria e método, que conta a história do Serviço social, mas não o serviço social na história. Isso recai sobre o próprio entendimento da centralidade do trabalho enquanto categoria e como modalidade da intervenção profissional, e sobre as expressões da "questão social" que explicam 
a própria existência da profissão e as mesmas como objeto da intervenção. Dissociadas nas disciplinas de FHTMS, encontramos o trabalho, a "questão social" e a transversalidade da ética e da pesquisa que ficam restritas às disciplinas específicas.

Não se trata aqui de apontarmos questões relativas apenas à questão da nomenclatura das disciplinas que abordam a ética, mas sim do universo conceptual daquilo que estamos denominando de lógica interna e pressupostos fundamentais. Cabe investigar mais a fundo de que forma o debate sobre os fundamentos ontológicos estão sendo garantidos nas disciplinas que focam a ética profissional, uma vez que foi recorrente nos Relatórios dos Regionais o destaque para uma desvinculação dos fundamentos ontológicos da discussão da ética. Obviamente que nos limites desse artigo não temos condições de realizar tal tarefa, mas vale ressaltar que desde a pesquisa sobre a implementação das diretrizes curriculares essa questão aparece como um dos grandes obstáculos ao entendimento da concepção de ética defendida no âmbito do projeto ético-político.

Esse dado amplia-se quanto à sua problemática quando é elencado o rol de disciplinas que tratam ou que garantem, para além da disciplina específica de ética, tal conteúdo. Aqui verificamos três que estão presentes em todos os Relatórios dos Regionais: 1) Estágio Supervisionado, 2) Pesquisa, (incluindo todas aquelas que se referem à construção do Trabalho de Conclusão de Curso - TCC e que foram citadas em todos os Relatórios), 3) Introdução ao Serviço Social. Em apenas três Relatórios (Norte, Sul I e Sul II), identificamos uma relação mais direta com o Núcleo de Fundamentos da Vida Social, na formação básica, versada nas disciplinas de Filosofia.

Os estudos de Barroco (2001; 2008; 2012) já evidenciaram, em profundidade, a relevância e necessidade histórica dos fundamentos ontológicos no debate sobre ética e vida social e na própria definição da concepção de ética defendida pelo projeto ético-político.

A reflexão ética é construída, historicamente, no âmbito da filosofia, tendo por objetivo a moral. Na perspectiva que nos orienta, ela é de caráter 
ontológico-social-materialista; busca, a partir da razão dialética, apreender, na totalidade sócio-histórica, as categorias ético-morais, desvelando suas particularidades e legalidades (BARROCO, 2001, p. 54-55).

Os fundamentos ontológicos são essenciais para que a crítica à sociabilidade do capital supere abordagens de caráter economicista, politicista ou eticista, por vezes presentes no universo profissional, e favoreça a apreensão da realidade de modo complexo, em suas múltiplas determinações. A crítica à vida cotidiana é, nesse sentido, fundamental no debate ético e não pode prescindir desses fundamentos, visto que:

A reflexão ética supõe a suspensão da cotidianidade; não tem por objetivo responder às suas necessidades imediatas, mas sistematizar a crítica da vida cotidiana, pressuposto para uma organização da mesma para além das necessidades voltadas exclusivamente ao "eu", ampliando as possibilidades de os indivíduos se realizarem como indivíduos livres e conscientes (BARROCO, 2001, p. 55).

Outro aspecto relevante refere-se ao entendimento sobre os direitos humanos, discussão presente no Serviço Social, notadamente por meio do universo da ética. No entanto, sem a apropriação dos fundamentos ontológicos, a tendência tem sido reproduzir a concepção de direitos humanos numa perspectiva liberal, sem vinculação com a totalidade social e consideração do caráter contraditório dos complexos sociais (SANTOS, 2007), na defesa da emancipação política, mas, perdendo de vista o horizonte da emancipação humana.

Um dos entraves ao aprofundamento teórico-metodológico no período da formação profissional reside no que já sinalizamos anteriormente e que Netto (1996) assinalou: o rebaixamento cultural do corpo discente. Hoje também nos cabe ampliar para o quadro docente. O primeiro cada vez mais jovem ingressa nas universidades, advindo de uma formação aligeirada e muito empobrecida. Nossos discentes, por sua vez, são o retrato do assolamento sociocultural de que as últimas gerações têm sido legatárias como um visível impacto do capitalismo no centro e na periferia. No caso dos docentes, o perfil das turmas do ABEPSS 
Itinerante revela a nova configuração dos cursos de Serviço Social no Brasil, com um número expressivo de jovens docentes com menos de 06 meses e até no máximo 05 anos de experiência docente. Esse quadro é também expressivo se observadas com cuidado a formação e qualificação desses docentes, na direta relação com seus processos de doutoramento, que foi antecedido da saída direta da graduação para o mestrado.

Nesse sentido, os Relatórios dos Regionais e as atividades coletivas de todo o país revelaram que o corpo discente apresenta dificuldades de leitura crítica da realidade e, portanto, tem limitações em apreender situações do cotidiano profissional, que tendem a rebater em demandas mais complexas como discussão coletiva, organização, planejamento, além da participação social e política e da capacidade de análise crítica da sociabilidade capitalista. Pensamos que essa realidade traz como elemento a ser bem mais estudado por nós o fato de que, embora tenhamos na vida cotidiana desses/as jovens um maior impacto desta realidade tornando-a real, concreta e objetiva, a exemplo da inserção precária no trabalho e/ou desemprego, da falta de acesso, dentre outras dimensões, à educação/saúde/cultura, isso não vem contribuindo para "facilitar" a compreensão da relação de exploração a que estão expostos. Ao contrário, apresentam dificuldades no entendimento das razões sócio-históricas que geram tais situações. Isso vem também se expressando na própria percepção valorativa (a partir de parâmetros morais, com horizonte de reflexão ética), na qual diferentes formas de violência, de opressão e de desrespeito aos direitos humanos são naturalizadas.

Para além dessas questões, merecem atenção dois grandes eixos de dificuldades apreendidos a partir das considerações elencadas por participantes do projeto ABEPSS Itinerante nos Relatórios dos Regionais.

O primeiro eixo remete àquilo que aludimos no início deste artigo e refere-se à lógica interna que articula a ética como uma dimensão transversal que tem caráter formativo. Por meio dos Relatórios, observamos que, ainda que a transversalidade tenha sido consensualmente afirmada, as dificuldades destacam a sua persistência focada muitas vezes numa disciplina específica e que 
acaba, também, por restringir-se aos/as docentes que ministram essa disciplina, pois como expresso em alguns relatórios poucos docentes dedicam seus estudos à ética e/ou sua fundamentação ontológica.

O fato de poucos professores se dedicarem aos estudos da ética, o que limita a construção da sua transversalidade na formação e, mas aqueles que aprofundam o conhecimento para garantir o conteúdo das disciplinas específicas (Relatórios dos Regionais Norte e Sul I);

No projeto pedagógico dos cursos, consta a ética como transversal, mas no cotidiano da formação a dimensão ética fica apenas em um único componente. Falta compreensão dos docentes dessa dimensão ética (Relatório Regional Sul II).

O segundo eixo de dificuldades relaciona-se aos pressupostos que afirmam a transversalidade da ética e que vão apresentar duas nuances, uma que se refere à própria compreensão da dimensão ontológica e outra que se refere ao quadro atual da sociabilidade vigente.

A primeira nuance aparece destacada nos Relatórios dos Regionais Leste e Nordeste, mas que entendemos como problemática postas à formação e ao exercício profissionais desde o início da década de 1990, e diz respeito as críticas ao marxismo, e que no campo da reflexão ética, remete a dimensão ontológica necessária para a compreensão da constituição dos valores. O que vem denominando-se de "Fundamentalismo teórico" (Relatório do Regional Leste), ou "Ditadura do Marxismo" (Relatório do Regional Nordeste). Do nosso ponto de vista evidencia tanto uma incompreensão da construção histórica da direção social da profissão quanto da apropriação da teoria social de Marx.

Quanto à construção da direção social da profissão, o grande desafio é do investimento para fortalecer, no campo da formação profissional, análises que remetam à densidade histórica do processo de renovação teórico-metodológica e ético-política do Serviço Social brasileiro. É muito mais do que conhecer e contar a história recente da profissão. Trata-se de apreender e aprender a ensinar para as novas gerações lições tecidas no cotidiano da 
vida social, no embate entre as classes sociais, entre projetos profissionais distintos no entendimento e na relação que a profissão estabelece com os movimentos sociais, com os usuários, frente ao Estado e às demandas e respostas profissionais.

A construção do que hoje denominamos projeto ético-político, por vezes, aparece como algo distanciado da realidade da sala de aula e, nesse movimento, as novas gerações tendem a naturalizar conquistas, desconhecendo ou destituindo de significado político sujeitos individuais e coletivos que, por meio de lutas por direitos com participação e articulação política dentro e fora do front do Serviço Social; de realização de estudos e pesquisas; da criação de cursos de pós-graduação na área e de muitas outras iniciativas relevantes, foram decisivas na construção de uma agenda profissional favorável ao entendimento real das situações de exploração, opressão e violação de direitos vivenciados pela maioria da população, que também, em potencial, os usuários do Serviço Social.

A direção social da profissão não é mera intencionalidade, é processo histórico real, com presença viva e desafiadora de sujeitos que se forjaram na luta; que dedicaram temporalidade e compromisso para que as entidades representativas, como a ABEPSS, o Conjunto CFESS-CRESS e a ENESSO, se constituíssem em espaços densos de debates, reflexões e tomadas de posicionamento, orientados por práticas democráticas e princípios e valores emancipatórios. Defender, portanto, uma profissão sem direção social é fortalecer o ideário conservador de que todos possuem a mesma intencionalidade, é negar a dimensão política das profissões. E como sabemos tão bem, quanto maior o clamor por neutralidade, mais intenso é o compromisso com a manutenção da realidade vigente.

Do nosso ponto de vista, afirmar a direção social não é subtrair nem destituir de sentido as diferenças teórico-metodológicas e ético-políticas existentes no ambiente do Serviço Social. Mas é reconhecer que há possibilidades de respostas profissionais bastante diferentes a partir do projeto que se defende. É na melhor das lições históricas admitir que na dinâmica cotidiana da vida social, as escolhas, os valores, as decisões têm lado, pois 
afirmam ou contrariam interesses de classe, os quais apresentam consequências concretas na vida cotidiana dos indivíduos.

Essa acusação de que a tendência teoricista presente no universo do Serviço Social seria determinada supostamente pela forte presença dos fundamentos da teoria marxiana e da tradição marxista na formação profissional indica a gravidade do momento histórico que vivemos. A luta pela continuidade da hegemonia capitalista num quadro de crise estrutural exige das classes dominantes alto investimento ideopolítico em disseminar modos de pensar e entender a realidade compatíveis, no limite, com a convivência pacífica com o capitalismo. Dissemina-se, notadamente entre os/as jovens estudantes, recém-chegados ao universo acadêmico, que o problema maior a ser enfrentado no âmbito da formação profissional é reduzir teoria e conduzir discentes à "prática". Nada tão enganoso. Contudo, trata-se de um discurso de fácil internalização, posto que encontra solo fértil favorável à sua reprodução, numa época em que a universidade em seu sentido amplo, e não apenas no horizonte dos cursos de Serviço Social, tende a conformação mais aberta ao projeto político das classes dominantes.

Não é à toa, portanto, o grande incentivo para que as novas gerações de discentes e docentes aceitem como seus, os projetos educacionais fundados na burocracia, no pragmatismo, no produtivismo, na competitividade, na pseudo-neutralidade, no relativismo e na acriticidade frente à realidade social. Como se de fato fosse possível estudar, trabalhar e viver sem assumir compromissos e desenvolver ações sem revelar uma dada direção social.

E novamente faz-se necessário questionar: a quem interessa o pragmatismo, a crença na possibilidade da neutralidade e a responsabilização no marxismo dos complexos limites identificados na formação profissional?

No caso da ética, essa voga aparece por meio do questionamento da possibilidade de valores universais que possam articular o gênero humano aos desafios da vida cotidiana com forte contraposição do relativismo cultural e da retomada da ética formalista. 
Há pouco aprofundamento acerca dos fundamentos teóricos da Ética, com isso a discussão fica centrada exclusivamente no ensino do Código de Ética (Relatório do Regional Centro-Oeste).

A segunda nuance é a que também já aludimos e que reporta a problematização e desafios para esta formação, transversalmente ética, num universo cujo peso do contexto social objetivo e o caldo cultural contemporâneo de neoconservadorismo exerce e se faz expressar no interior da formação e do exercício profissionais. Nesse sentido, requisita-se que a dimensão ética não seja tratada apenas como uma disciplina, mas como parte do universo categorial que deve ser pensado e perpassado na formação para a análise e intervenção profissional ${ }^{4}$. Em outras palavras, trata-se

Da dificuldade do "movimento de desconstruir valores oriundos de uma sociedade pautada no individualismo e nos valores capitalistas do consumismo, divisão de classes e preconceito e construir novos valores de uma sociedade mais justa, igualitária, em um tempo muito reduzido" figura como um dos maiores problemas a serem enfrentados na reflexão sobre a necessária transversalidade da ética (Relatório do Regional Sul I).

A reflexão crítica sobre os valores deve ser problematizada ao longo da formação profissional. Por outro lado, essa necessária "provocação" associada à crítica radical tem trazido inseguranças e conflitos para discentes e docentes, o que exige maior interação com as outras disciplinas que compõem a matriz curricular para assegurar uma direção crítica comprometida com valores humanistas concretos.

Cabe destacar a ênfase na subjetividade, que aparece no Relatório do Regional Centro-Oeste e que deve ser objeto de atenção. Trata-se do entendimento que credita a "sensibilidade do professor" o trato da Ética. Como se o campo dos valores não fosse constituído a partir da objetividade social. Aqui verificamos

4 Não estamos negando a necessidade de conteúdos específicos sobre a ética profissional e a garantia de seu espaço enquanto disciplina, mas defendendo a necessidade da transversalidade da ética em sentido mais amplo. 
mais um elemento de subjetivismo que expressa entre os docentes esse caldo cultural que estamos considerando.

Avalio que a questão é dependente do comprometimento docente para a sua efetivação (Relatório do Regional Centro-Oeste)

Sobre a objetividade que funda os valores, Barroco (2001, p. 29) analisa:

\begin{abstract}
Assim como as escolhas, a orientação de valor é inerente às atividades humanas; sua criação é objetiva, também gerada a partir do trabalho. Para transformar a natureza, o homem desenvolve um certo nível de conhecimento que lhe permite saber quais são as formas apropriadas para essa intervenção [...] Assim se coloca o caráter objetivo dos valores, eles sempre correspondem a necessidades e possibilidades sócio-históricas dos homens em sua práxis.
\end{abstract}

Como dimensão transversal, o ensino da ética deve se efetivar para além de disciplinas específicas, e se constituir, também no sentido mesmo de transversalidade formativa no campo dos valores e de uma atuação crítica diante da sociedade burguesa. No caso da pesquisa, a concepção de pesquisa presente nas diretrizes aponta para a dimensão investigativa como componente indissolúvel da intervenção profissional. Neste sentido, apesar dos avanços nas atividades desenvolvidas junto às turmas, verificamos que ainda temos que avançar na construção da transversalidade da ética, garantindo consciente direcionamento e intencionalidade frente aos fundamentos teórico-metodológicos adotados na formação e apropriação por diferentes docentes dos conteúdos e perspectiva ética anunciada nas diretrizes. Trata-se de assumir a ética como reflexão ontológica e, nesse sentido, de acordo com Barroco (2001, p. 55):

[...] a ética possibilita a elevação aos valores humano-genéricos, mas sua necessária abstração teórica não a isola da práxis; como filosofia crítica interfere indiretamente na realidade, contribui para a ampliação das capacidades ético-morais. 
Assim, o desafio é a constituição de um sujeito profissional capaz de agir moralmente, com vistas a um horizonte efetivamente emancipatório. A dimensão da ética é trazida e tratada na lógica curricular como dimensão transversal, ainda que se guarde a especificidade da disciplina de ética profissional. Do nosso ponto de vista, essa transversalidade vincula os componentes curriculares às competências e habilidades do perfil profissional que se quer formar. Em outras palavras, diante do processo de barbarização das relações sociais e de todas as formas de violação que homens e mulheres vêm sofrendo na ordem do capital (homofobia, preconceito étnico, marginalização e criminalização da pobreza, violência contra a mulher) nunca se fez tão necessário o posicionamento crítico e a radicalização de valores realmente pautados na emancipação humana e na plena realização dos sujeitos sociais.

\section{A NECESSÁRIA CENTRALIDADE DA ÉTICA NA FORMAÇÃO PROFISSIONAL DAS/OS ASSISTENTES SOCIAIS}

Ela está no horizonte - disse Fernando Birri -. Aproximo-me dois passos, ela se afasta dois passos. Caminho dez passos e o horizonte corre dez passos adiante. Por mais que eu caminhe, nunca a alcançarei. Para que serve então a utopia? Para isso serve:

para caminhar.

(Ventana sobre la utopia - Eduardo Galeano)

Cabe-nos agora, apontar aqui o que estamos entendendo por formação profissional, para então explicar porque consideramos necessária a centralidade da ética nesta formação, dialogando com dimensões do conteúdo apresentado sobre a experiência do projeto ABEPSS Itinerante, na perspectiva de sinalizar alguns possíveis caminhos na construção de tal transversalidade e dos conteúdos e formatos fundamentais ao ensino da ética profissional garantindo, também, sua especificidade na formação de futuros assistentes sociais

Ao nos referirmos à formação profissional (em sua especificidade na graduação), estamos compreendendo o processo vivenciado por estudantes do curso de Serviço Social para se habilitarem ao trabalho profissional. Esse, claro, é apenas o início 
de uma caminhada que, em nosso entender, deve ser continuada, visto que tanto nós, como a realidade, vivemos em contínuo processo de transformação.

Assumindo a ideia de um processo que é informativo e formativo, estamos apontando a importância dessa formação no que diz respeito não só ao acesso às diferentes informações, mas, e, em especial, ao processo de formação não só de um profissional, mas de um sujeito social que terá na graduação a possibilidade de ver e rever seus valores e práticas, suas posturas na relação com o outro, mas, sobretudo superar, dentre outras questões, entendimento formulado no senso comum do Serviço Social, da sociedade, do papel do Estado, das necessidades sociais e dos interesses dos indivíduos

Por intermédio do gesto de ensinar, o professor, na relação com os alunos, proporciona a eles, num exercício de mediação, o encontro com a realidade, considerando o saber que já possuem e procurando articulá-lo a novos saberes e práticas. Possibilita aos alunos a formação e o desenvolvimento de capacidades e habilidades cognitivas e operativas (LIBÂNEO, 1991: 100) e, com isso, estimula-os a posicionar-se criticamente diante do instituído, transformando-o, se necessário (RIOS, 2001, p. 52).

Formação que possibilite:

[...] capacidade de crítica teórica, consistência histórica mais refinamento político, habilidade para projeções estratégicas no desempenho de atividades técnicas e políticas, e mais, superação de perspectivas reducionistas e unilaterais como praticismo, teoricismo, ecletismo e voluntarismo (PAIVA; SALES, 1996, p. 205).

[...] Formação de profissionais qualificados para investigar e produzir conhecimentos sobre o campo que circunscreve sua prática, de reconhecer o seu espaço ocupacional no contexto mais amplo da realidade sócio-econômica e política do país e no quadro geral das profissões (IAMAMOTO, 1992, p. 163).

Trata-se, portanto, de uma formação profissional que é também formação ética, numa dada perspectiva de ética profissional. 
Daí decorre nossa afirmação: A formação profissional tal qual por nós defendida, em consonância com o projeto ético-político, só pode se realizar em havendo uma centralidade da ética neste processo.

Ao compreendermos a formação profissional como espaço de formação mais ampla do ser humano numa lógica não mercadológica, mas sim de totalidade, podemos afirmar a existência de um vínculo orgânico entre projeto profissional, projeto de educação e de universidade e projeto societário. Vínculo orgânico que não se estabelece no cotidiano de modo mecânico, mas mediado por um conjunto de questões e interesses que devem sinalizar para a defesa de uma educação que supõe formar pessoas para a vida, para o mundo e não somente para o exercício profissional; e, para tanto, pressupõe o fomento do pensamento crítico que possibilite uma ação reflexiva e competente ${ }^{5}$.

Integra, portanto, o cotidiano da docência a busca por contribuir em processos mais amplos de disseminação de um projeto societário e profissional que revelam modos de entender e intervir na realidade de forma crítica. Nas palavras de Cortella, identificamo-nos enquanto docentes, movidas por uma busca dotada, entre outros elementos, pela paixão;

Paixão por uma ideia irrecusável: gente foi feita pra ser feliz! E é esse o nosso trabalho (de educadores e educadoras); não só nosso, mas também nosso. Paixão pela inconformidade de as coisas serem como são; paixão pela derrota da desesperança; paixão pela idéia de, procurando tornar as pessoas melhores, melhorar a si mesmo ou mesma; paixão, em suma, pelo futuro (CORTELLA, 1998, p. 157).

Ora, se defendemos uma formação que consiga se realizar dessa forma, de que mais estamos falando, senão de uma formação profissional que deve pressupor a reflexão ética? ${ }^{6}$ Especificamente quanto ao Serviço Social, nos apresentam Brites e Barroco (2000, p. 26):

5 Referimo-nos à competência teórica, ética e técnica e não a competência instrumental produtivista.

6 Não nos referimos à formação apenas de assistentes sociais, mas de todo profissional. 


\begin{abstract}
A formação ética, por sua natureza filosófica, é pressuposto essencial, tanto para o desvelamento crítico do significado das escolhas individuais em face dos projetos coletivos, quanto para orientar a construção de respostas profissionais que, diante dos desafios cotidianos, tenham a capacidade objetiva de romper, em algumas situações, ou de resistir aos limites da ordem burguesa.
\end{abstract}

Nesta perspectiva, contrapomo-nos a realidade que infelizmente encontramos no que diz respeito ao lugar que a ética ainda hoje ocupa na formação dos/as assistentes sociais, como vimos no item anterior: o da especificidade da disciplina. Não deve ser este seu único espaço!

É inegável o avanço do debate da ética na formação profissional, em especial nas últimas duas décadas, enquanto espaço/ lugar e qualificação deste numa direção crítica e possibilitadora de processos de transformação dos sujeitos ${ }^{7}$, apontando para a coerência de uma formação que busque os fundamentos da ontologia do ser social, tendo como centrais a liberdade e a emancipação humana.

Tal debate, no seio da categoria, ganha relevância e espaço a partir, sobretudo, dos anos $1990^{8}$. Do ponto de vista da formação profissional, esse espaço vai se fortalecendo também nesta década e vem sendo aprofundado mais efetivamente nos anos 2000. Assim, embora já tenhamos muitos frutos sobre a discussão da ética na formação ${ }^{9}$ e no exercício profissionais (artigos, livros, inserção nos debates e eventos, assunção da temática nas mesas

7 Referimo-nos aqui à ideia da contribuição aos diferentes processos que possibilitam revisão de valores, posturas, reflexões e posicionamentos no mundo.

8 A discussão de ética e, em específico da ética vinculada à formação profissional, passa a constar dos eixos temáticos de discussão do Congresso Brasileiro de Assistentes Sociais (CBAS), apenas a partir de sua VII edição, em 1992. A apresentação de trabalhos nas sessões temáticas sobre ética ou sobre formação profissional que envolva uma relação entre esses dois temas, ainda é muito pequena. Em pesquisa realizada por Cardoso (2006), nota-se que do VII ao XI CBAS, o percentual de trabalhos apresentados na modalidade de comunicação oral, quer seja na sessão temática de ética, quer seja na de formação profissional, discutindo especificamente a ética na formação variou entre $0 \%$ a 16,7\% do total de trabalhos apresentados em cada uma destas sessões.

9 Vale destacar as produções de Barroco (2001; 2008). 
de CBAS e ENPESS, etc), ainda temos lacunas a serem superadas no que diz respeito, dentre outras, aos projetos político-pedagógicos e sua concretização nas UFA.

Ao observarmos os currículos mínimos existentes para os cursos de Serviço Social desde 1953 até as diretrizes de $1996^{10}$ identificamos o salto da discussão da ética em dois sentidos: 1)o espaço que esta ganha enquanto disciplina; 2)- a qualificação que vai tendo na mudança de perspectiva na disciplina de ética profissional ${ }^{11}$.

Porém, embora observemos tal avanço e as diretrizes de 1996 traduzam um esforço em tratar a ética em sua transversalidade $^{12}$, a realidade ainda encontrada na maioria das UFA (como vimos nos relatos dos participantes do projeto ABEPSS Itinerante), é a da discussão da ética circunscrita ao espaço da disciplina de ética profissional, sendo, em alguns poucos casos, mais articulada com a discussão dos Fundamentos filosóficos para o Serviço Social.

Ainda é bem comum o debate da ética restrito à discussão que o/a docente responsável pela disciplina de ética profissional realiza, não conseguindo, portanto, perpassar os conteúdos de outras disciplinas numa coerência conceitual teórica e política com a perspectiva trabalhada em ética profissional.

Sabemos, porém, que dilemas éticos estarão sempre presentes nos conteúdos de outras disciplinas, mesmo que não seja de modo articulado pelo/a docente, o que propicia que muitas vezes, os conteúdos éticos surgidos dos debates e aulas em cada disciplina acabem sendo tratados sem coerência com os conteúdos

10 Tal análise e os currículos originais podem ser vistos em Cardoso (2006).

11 Antes do $1^{\circ}$ currículo mínimo (Lei № 1889 de 13 de Junho de 1953), podemos observar como se apresentava a questão da ética no $1^{\circ}$ curso de Serviço Social do Brasil. Na matriz curricular da escola Sabará, de 1936 a 1945, vemos a presença da Ética apenas a partir de 1940 (aparecendo com o nome Ética Profissional), ano em que a disciplina de Religião também passa a figurar na mesma matriz. No entanto, desde 1937, a disciplina de Moral já compunha o currículo, mantendo-se presente mesmo após a entrada da disciplina de ética profissional.

12 Vale frisar que ao lermos as diretrizes, encontramos tal esforço assumido na apresentação dos Núcleos de Fundamentação, mas não demonstrado enquanto possibilidade na concretude das disciplinas sugeridas. 
da disciplina específica de ética profissional, bem como, com as referências expressas em nosso Código de Ética.

Neste sentido, vale destacar a importância da eleição desse tema como um dos eixos trabalhados no projeto ABEPSS Itinerante. Os relatos dos participantes, embora apresentem o consenso sobre a importância da transversalidade da ética, confirmaram a dificuldade de sua materialização, havendo ainda um distanciamento da discussão da ética de outras disciplinas, bem como confirmam a necessária formação de docentes para um alinhamento conceitual da perspectiva ética adotada na profissão nas três últimas décadas.

Defender a concepção de ética na formação nos termos aqui trabalhados significa compreender, que formação profissional pressupõe articulação de conteúdos, pois senão falamos de informação e não formação profissional.

Sabemos, pois, das dificuldades concretas e objetivas, além das subjetivas, que marcam a efetivação de tal articulação $^{13}$ e, nesse sentido, gostaríamos de frisar a importância da busca de respostas coletivas para o enfrentamento dessas dificuldades, o que nos remete ao fundamental papel das entidades de organização da categoria, em especial a ABEPSS e o conjunto CFESS-CRESS, bem como, no interior das unidades de ensino; a necessária articulação entre docentes, discentes e destes com as entidades de maneira a subsidiarem a elaboração de tais propostas coletivas.

Faz-se necessário, também, a apreensão do exercício da docência como um dos trabalhos profissionais que deve ser pensado e compreendido no conjunto dos diferentes espaços de trabalho do/a assistente social. Não é raro ouvirmos a pergunta: além de dar aula você atua como assistente social? Ou então, você realiza alguma prática profissional?

A docência em Serviço Social, nas disciplinas específicas de matéria em Serviço Social, é função precípua de assistentes sociais, bem como, a universidade é um espaço sócio-ocupacional

13 Várias delas aparecem nos relatos dos participantes no processo de formação em cada regional da ABEPSS, conforme apresentado no item anterior. 
no qual se desenvolve o trabalho do/a assistente social com todas as características apontadas por lamamoto (1998) quanto a este.

Tais questões - da necessária articulação de conteúdos, do encontro de saídas coletivas às dificuldades para esta articulação e do entendimento da docência como trabalho profissional do/a assistente social - são fundamentais para a busca de espaços de articulação desses conteúdos interna e externamente a cada unidade de formação acadêmica. A busca e concretização desses espaços urgem, para que a formação possa ser realmente formação e não informação, e para que as diferenças de concepção e referências possam se explicitar, evidenciando projetos profissionais em disputa no cotidiano acadêmico.

No que diz respeito à ética e sua transversalidade, é só na criação desses espaços de troca de saberes e de avaliação do processo formativo, que se efetivará a possibilidade quanto ao entendimento da teleologia da disciplina de ética profissional, que aponta para uma perspectiva, que mesmo que não seja a do corpo docente como um todo, necessita ser por este compreendida e apropriada nas discussões junto ao corpo discente, uma vez que temos um Código de Ética orientador da postura profissional, não podendo haver, portanto, nem desconhecimento nem desconsideração por parte do corpo docente, em sala de aula, sobre o preconizado em tal Código. Faz-se fundamental:

[...] a capacitação ética do corpo docente, a coerência teórica entre as disciplinas especialmente responsáveis pelo ensino da ética - filosofia e ética profissional-, a responsabilização de todos os sujeitos envolvidos na formação - com especial atenção para a responsabilidade do educador-, a reflexão ética sobre os estágios, a elaboração de uma política de estágios regida pelo Código de Ética e, portanto, responsável pela omissão em face de determinadas situações que merecem ser denunciadas ética e politicamente (BRITES; BARROCO, 2000, p. 30).

Vale destacar que possíveis discordâncias em relação ao conteúdo do código de ética profissional devem ser tratadas no ambiente coletivo criado historicamente pelo Serviço Social brasileiro, neste caso específico o Encontro Nacional CFESS-CRESS, 
espaço de decisão e de deliberação da agenda profissional. Se considerarmos a dinâmica assegurada pelo CFESS na condução político-organizativa desse encontro fica explícito o quanto não procede a crítica dos opositores do projeto ético-político de que há imposição e/ou ausência de reflexão e espaço de debate sobre a direção social da profissão ${ }^{14}$. O mesmo podemos afirmar em relação à condução política da ABEPSS no processo de elaboração e aprovação das diretrizes curriculares e nas iniciativas que deram continuidade à implementação e avaliação desse processo ${ }^{15}$.

De modo tal que os/as discentes precisam ter conhecimento dos espaços e da dinâmica de debates e decisões construídas de modo democrático no Serviço Social brasileiro, uma vez que ter projetos profissionais e societários em disputa não é em si um problema. Ao contrário, revela modos distintos de entender a realidade e a profissão e quanto mais os explicitarmos e colocarmos em discussão, maior as possibilidades de fortalecimento de nossa direção. Mesmo no âmbito do projeto ético-político sobressaem polêmicas e tensões, próprias de uma profissão que lida com complexas situações e expressões da vida social e da vida dos indivíduos.

Neste sentido, não defendemos um projeto de formação profissional enquanto camisa de força ou mera imposição, mas como processo que é histórico, denso e permeado por conquistas, compromissos, derrotas coletivas nas estratégicas lutas por emancipação política e necessária apropriação de consciência de classe e conhecimento profundo da realidade. Certamente nada disso se constitui como algo fácil, é um convite permanente

14 O que não significa que novos e amplos espaços não devem continuar a ser criados, como também têm feito o conjunto CFESS/CRESS e ABEPSS, levando em consideração a necessidade de discussões descentralizadas e cada vez mais próximas ao conjunto da categoria, a exemplo dos seminários nacionais sobre o exercício profissional em diferentes áreas promovidos de forma gratuita pelo Conjunto CFESS-CRESS.

15 Essa observação torna-se tão mais relevante quanto mais se amplia na base social, e a profissão também vem expressando isso por meio dos seus sujeitos profissionais, a recusa dos espaços coletivos como espaços efetivos de construção/desconstrução, defesas, críticas e aprofundamentos das questões. Na tônica dominante os espaços coletivos são cada vez mais esvaziados seja para o campo da judicialização, ou da individualização mesma, que contribui cada vez mais para a garantia da hegemonia burguesa. 
e aberto à reflexão crítica, num entendimento de que não há estado absoluto de ser docente e assistente social. Vamos, como um grande desafio, aprimorando o tornar-se profissional, numa tarefa que é simultaneamente individual e coletiva.

\section{CONSIDERAÇÕES FINAIS}

É necessário, em nosso entendimento, o alinhamento da referência ética na perspectiva da ontologia do ser social, junto ao corpo docente, o que pressupõe processos formativos contínuos também dos/as docentes. E aqui, gostaríamos de frisar a importância de continuidade do projeto ABEPSS itinerante, que foi semeador desse caminho já em sua primeira edição, podendo, a partir da avaliação desta, se fortalecer e ampliar, alcançando mais UFA e profissionais.

Outra estratégia importante no sentido da articulação de conteúdos e do alinhamento conceitual acerca da ética profissional diz respeito à explicitação da teleologia desta disciplina nos planos de ensino, bem como, a explicitação dos objetivos a cada unidade programática, de maneira a tornar visível sua intencionalidade e os passos para a concretização desta.

Trata-se, pois, da necessária especificidade de disciplinas que tratem à ética (seus fundamentos) e a ética profissional. A afirmação da transversalidade da ética em todo o currículo, de maneira alguma descaracteriza a sua importância e necessidade enquanto conteúdo específico a ser abordado em disciplina(s) determinada(s).

O fato é que alguns conteúdos são essenciais à preparação da discussão específica da ética profissional e devem ter espaço e tempo no currículo, o que significa pensar seriamente a carga horária, conteúdo e estratégias de articulação dessas disciplinas nas matrizes curriculares ${ }^{16}$.

E qual a teleologia que esta disciplina deve ter, ou seja, para que devem servir seus conteúdos? Em que direção a ética profissional enquanto disciplina contribui para a formação profissional?

16 Disciplinas tais como Fundamentos Filosóficos para o Serviço Social, Fundamentos éticos da vida social, entre outras, como vimos no relato das regionais no processo do ABEPSS Itinerante. 
Acreditamos que a disciplina deve ter como teleologia, como finalidade: preparar os/as discentes para o enfrentamento das questões éticas que perpassaram o cotidiano profissional, numa determinada direção, expressa em nosso Código de Ética, que é radicalmente contrária a todo e qualquer tipo de preconceito e autoritarismo, visto que é a expressão da compreensão da ética na perspectiva ontológica, que nos dá fundamento para a busca da reflexão ética enquanto possibilidade de saída da alienação própria do cotidiano na sociabilidade do capital, transcendendo o espaço da moral e podendo realizar escolhas livres, conscientes e críticas na direção do reconhecimento de nossa singularidade e ao mesmo tempo, de nossa genericidade humana.

Para tanto, é imprescindível questionar princípios, valores, o que na maioria das vezes, inquieta e desassossega a individualidade e subjetividade do/a aluno/a, no seu processo de formação profissional, pois este não poderá ser um profissional livre de preconceitos e com atitudes éticas, no sentido do reconhecimento da genericidade humana, se for uma pessoa preconceituosa que compreenda seu lugar no mundo e sua relação com o outro, apenas na sua singularidade.

E essa compreensão demonstra claramente que esse processo não pode e não deve dar-se apenas no âmbito de uma disciplina, pois supõem necessariamente muito além dela. Neste caso, trata-se mesmo de como podemos garantir e efetivar que a transversalidade compareça efetivamente no trato de todas as disciplinas que englobam a formação profissional favorecendo a compreensão ética e ação ética como partes constitutivas dos encaminhamentos do estágio supervisionado, no pensar a atuação profissional nas políticas sociais, no planejamento e na gestão das políticas. Ou seja: Como este sujeito profissional em formação vai conseguir matizar sua intervenção profissional de maneira eticamente direcionada?

Ora, o que estamos dizendo é que pessoal e profissional, neste sentido, não se separam. E, neste caso, tamanho é o desafio que se coloca quando a busca por uma formação universitária tem sido vislumbrada como tão somente passaporte para empregos mais instáveis e muito menos como exercício de uma 
profissão cuja intervenção tem impacto direto, efetivo e real na vida de homens e mulheres.

Por outro lado, como a própria realidade do projeto ABEPSS Itinerante mostrou, tem sido quase que exclusivamente por meio da disciplina de ética que os discentes têm sido convidados a "reverem" seus conceitos e preconceitos. Nesse sentido, urge redimensionar esta questão na formação e ao mesmo tempo precisamos intensificar a compreensão de sua teleologia que deve apontar para a formação de futuros profissionais tendo como finalidade a preparação do/a estudante para o exercício de sua capacidade ética, na realização de escolhas livres, conscientes e críticas, diante dos conflitos éticos postos pela sociedade capitalista, nas respostas individuais e coletivas da categoria à questão social e suas manifestações, o que envolve a preparação imbricada da postura ética para a vida e da postura ética para a ação profissional na direção da construção de uma vida feliz ${ }^{17}$, e, portanto, na contribuição da construção de outra sociabilidade.

Diante de tal teleologia e para que ela se objetive, é necessário refletirmos sobre o ethos da própria disciplina, ou seja, o seu modo de ser, o que inclui pensarmos não só seus conteúdos, mas a forma como estes serão trabalhados.

Nesse sentido, gostaríamos de pontuar alguns elementos a serem vistos como socialização de estratégias na execução de tal disciplina.

- Vinculação da disciplina à perspectiva da compreensão ontológica do ser social;

- Entendimento e utilização do Código de ética como um dos elementos da disciplina, não restringindo todo seu conteúdo programático ao ensino e socialização do Código, mas sim a reflexão sobre os elementos econômicos, sociais, culturais presentes na realidade concreta, que envolvem a objetivação de determinados valores deste Código;

- Apropriação das dimensões que compõem a ética profissional e sua unidade-diversa num movimento dialético;

17 A este respeito, ver Rios (2001). 
- Recorrência a uma metodologia que propicie a interiorização dos conteúdos essenciais, com desenvolvimento de estratégias que favoreçam a reflexão crítica e à formação da consciência de classe articulada ao reconhecimento e valorização dos projetos coletivos, da singularidade e da diversidade humana.

- Ênfase teórico-prática aos conteúdos, para que seja possível a internalização dos valores propostos no Código, bem como a compreensão da ética como práxis;

- Desenvolvimento de temas essenciais, tais como: ser social, trabalho, teleologia, historicidade, totalidade, vida cotidiana, valores, moral, conflito moral, alienação, ética, singularidade/ genericidade humana, ética profissional, projetos coletivos/individuais; projetos societários e profissionais;

- Tratamento da questão ética na profissão observando sua historicidade, o que significa demonstrar a existência de diferentes projetos e éticas profissionais, expressos nos cinco Códigos de Ética como produto de um processo histórico;

- Utilização de bibliografia vinculada à concepção da ética na perspectiva ontológica: nos clássicos - Heller, Lukács, Marx, e nas suas interpretações e diversas contribuições no universo da produção bibliográfica crítica no Serviço Social brasileiro e áreas afins. Criação de material didático-pedagógico que facilite a compreensão da bibliografia anteriormente citada. É necessário maior produção e discussão neste sentido;

- Recorrência sistemática a outros recursos para além de leitura e discussão de textos e/ou aulas dialogadas ou expositivas, quer sejam: filmes, dinâmicas, dramatizações, visitas monitoradas, exercícios reflexivos sobre a realidade, entre outros;

- Concretização dos temas, categorias e conceitos trabalhados a partir de sua mediação com a realidade social e com o cotidiano, na discussão sobre questões éticas presentes nestes.

Muitos são os desafios presentes nesta forma de pensar a ética na formação profissional dos/as assistentes sociais, tanto no que diz respeito à sua transversalidade, quanto a sua especificidade.

Durante o processo formativo propiciado pelo ABEPSS Itinerante, vários desafios e estratégias foram apontados, 
mostrando o quanto espaços coletivos para formação são fundamentais para socialização do entendimento sobre a realidade e a construção coletiva de respostas a essa e aos inúmeros e complexos desafios. Retomamos alguns deles neste artigo, outros tantos ainda se colocam e merecem nosso conhecimento e enfrentamento, na construção coletiva de ações que possibilitem a objetivação de nosso projeto ético-político na formação profissional dos/as assistentes sociais.

O projeto ABEPSS Itinerante deu um importante passo nesta construção, porque possibilitou socializar, refletir e debater aspectos fundamentais em cada um dos seus módulos. Em relação ao módulo de Ética, tivemos um enorme ganho ao refletirmos sobre os fundamentos ontológicos e sócio-históricos fundamentais em sua relação com as questões concretas do cotidiano. É óbvio que o tempo foi insuficiente para a complexidade das questões abordadas. O aprofundamento incessante dessa experiência tem que se realizar no universo das UFA e em diferentes iniciativas que envolvam os docentes, discentes, grupos de pesquisa, supervisores de estágio (acadêmico/campo) e movimento estudantil. É no cotidiano onde certamente residem as maiores dificuldades e desafios, pois se trata de defender uma determinada concepção de ética, de projeto profissional e societário voltados à emancipação humana, numa conjuntura sócio-histórica de avanço do conservadorismo e de naturalização da barbárie como estratégias impostas pelo capital à vida social e à reprodução dos indivíduos.

\section{REFERÊNCIAS}

BARROCO, Maria Lúcia Silva. Ética e Serviço Social: Fundamentos ontológicos. São Paulo: Cortez, 2001.

- Ética: fundamentos sócio-históricos. Biblioteca básica para o Serviço Social. Vol. 04. São Paulo, Cortez, 2008.

BARROCO, Maria Lúcia Silva. Materialidade e potencialidades do Código de ética dos Assistentes Sociais brasileiros - Parte I. In: CFESS (org.). Código de ética do/a assistente social comentado. São Paulo: Cortez, 2012. 
BRITES, Cristina M.; BARROCO, M. Lúcia. A centralidade da ética na formação profissional. Revista Temporalis, Brasília, ABEPSS, Valci, n. 2 - Diretrizes curriculares: polêmicas e perspectivas, 2000.

CARDOSO, Priscila F. G. Havia uma ética no meio do caminho? A afirmação da necessária centralidade da ética na formação profissional dos assistentes sociais. Tese (Doutorado) - PUC, São Paulo, 2006.

CORTELLA, Mário Sérgio. A escola e o conhecimento: fundamentos epistemológicos e políticos. São Paulo: Cortez - Instituto Paulo Freire, 1998.

IAMAMOTTO, Marilda Villela. Renovação e Conservadorismo no Serviço Social: Ensaios Críticos. São Paulo: Cortez, 1992.

. O Serviço Social na contemporaneidade: trabalho e formação profissional. São Paulo: Cortez, 1998.

- O Serviço Social na cena contemporânea. In: CFESS/ ABEPSS. Serviço Social: direitos sociais e competências profissionais. Brasília: CFESS/ABEPSS, 2009.

NETTO, José P. Transformações societárias e Serviço Social - notas para uma análise prospectiva da profissão no Brasil. Revista Serviço Social e Sociedade, São Paulo, Cortez, n. 50, 1996.

PAIVA, Beatriz A.; SALES, Mione A. A Nova Ética Profissional: Práxis e Princípios. In: BONETTI, Dilsea Adeodata; SILVA, Marsile Vinagre; GONELLI, Valeria M. M. Serviço Social e Ética: convite a uma nova práxis. São Paulo: Cortez, 1996.

RIOS, Terezinha A. Compreender e ensinar: por uma docência da melhor qualidade. São Paulo: Cortez, 2001.

SANTOS, Silvana Mara Morais. Direitos humanos, dominação ideológica e resistência. Revista Inscrita, Brasília: CFESS, n. 10, 2007.

- Direitos, Desigualdade e Diversidade. In: BOSCHETTI, Ivanete et al (Org.). Política Social no Capitalismo: tendências contemporâneas. São Paulo: Cortez Editora, 2008. p. 64-86. 